Retraction Note

\title{
Retraction Note to: Application in optimization of multi-reservoir water systems using improving shuffled complex algorithm
}

\author{
Mohsen Najarchi ${ }^{1}$. Amir Haghverdi ${ }^{2}$
}

Published online: 29 September 2020

(c) Springer Nature Switzerland AG 2020

\section{Retraction Note to: \\ SN Applied Sciences (2020) 2:896 \\ https://doi.org/10.1007/s42452-020-2590-x}

The Editors have retracted this article [1] because it contains material that substantially overlaps with the following articles $[2,3]$.

All authors agree to this retraction.

\section{References}

1. Najarchi M, Haghverdi A (2020) Application in optimization of multi-reservoir water systems using improving shuffled complex algorithm. SN Appl Sci 2:896. https://doi.org/10.1007/ s42452-020-2590-x

2. Nezhad OB, Najarchi M, NajafiZadeh MM, Hezaveh S, Mirhosseini M (2018) Improving shuffled complex evolution algorithm and its application in optimization of multi-reservoir water systems. Fresenius Environ Bull 27(9):6100-6108

3. Nezhad OB, Najarchi M, NajafiZadeh MM, Hezaveh SM (2018) Developing a shuffled complex evolution algorithm using a differential evolution algorithm for optimizing hydropower reservoir systems. Water Sci Technol Water Supply 18(3):1081-1092. https://doi.org/10.2166/ws.2017.179

Publisher's Note Springer Nature remains neutral with regard to jurisdictional claims in published maps and institutional affiliations.

The original article can be found online at https://doi.org/10.1007/s42452-020-2590-x.

Mohsen Najarchi, m-najarchi@iau-arak.ac.ir | 'Department of Water Science Engineering, Arak Branch, Islamic Azad University, Arak, Iran. ${ }^{2}$ Department of Environmental Science, University of California Riverside, Riverside, USA. 